УДК 343.121 .5

\title{
Г.А. Решетникова
}

\section{ПОНЯТИЕ «НАЦИОНАЛЬНЫЕ ИНТЕРЕСЫ» В КОНТЕКСТЕ НАЦИОНАЛЬНОЙ БЕЗОПАСНОСТИ РОССИЙСКОЙ ФЕДЕРАЦИИ}

\begin{abstract}
«Национальные интересы» составляют основу формирования внешней и внутренней политики государства. Объективным показателем этого является совокупность социально-экономических, политикоорганизационных, правовых действий органов власти и управления по их реализации. Практическая целесообразность явления «национальные интересы» зависит от его теоретической состоятельности. Как новое явление для современной России «национальные интересы» требуют осмысления и научной разработки. Руководствуясь положениями политико-правовых документов в сфере обеспечения национальной безопасности Российской Федерации, опираясь на результаты, полученные исследователями в области философии, политологии, теории и истории права и государства, истории правовых и политических учений, этнографии и т.д., автором статьи предпринят поиск концептуальной природы и сущностных свойств этого многокомпонентного явления.
\end{abstract}

Ключевые слова: безопасность, государство, государственность, нация, национальные интересы, национальная безопасность, объективно значимые интересы личности, общества и государства.

DOI: $10.35634 / 2412-9593-2020-30-3-438-444$

Базовым документом для формирования и реализации государственной (внутренней и внешней) политики в сфере обеспечения национальной безопасности России является Стратегия национальной безопасности Российской Федерации (далее - Стратегия 2015 г.) ${ }^{1}$. Этим документом определяются национальные интересы, стратегические национальные приоритеты России, цели, задачи и меры, направленные на укрепление национальной безопасности и обеспечение устойчивого развития страны на долгосрочную перспективу. В соответствии с ч. 4 ст. 18 Федерального закона № 172-Ф3 от 28 июня 2014 г. «О стратегическом планировании в Российской Федерации» Стратегия национальной безопасности Российской Федерации является основой для конструктивного взаимодействия органов государственной власти, организаций и общественных объединений в целях защиты национальных интересов Российской Федерации и обеспечения безопасности личности, общества и государства 2 . Являясь основой для государственной политики, Стратегия 2015 г. призвана консолидировать усилия органов государственной власти, органов местного самоуправления и институтов гражданского общества по созданию благоприятных внутренних и внешних условий для реализации национальных интересов и стратегических национальных приоритетов с помощью политических, военных, организационных, социально-экономических, информационных, правовых и иных мер, направленных на противодействие угрозам национальной безопасности и удовлетворение национальных интересов ${ }^{3}$. Следовательно, национальные интересы - это базовое, смыслообразующее понятие национальной безопасности. Это утверждение согласуется с легальными понятиями «национальные интересы» и «национальная безопасность». Согласно п. 6 Стратегии 2015 г., национальные интересы Российской Федерации - это объективно значимые потребности личности, общества и государства в обеспечении их защищенности и устойчивого развития ${ }^{4}$. Национальная безопасность Российской Федерации определяется как состояние защищенности личности, общества и государства от внутренних и внешних угроз, при котором обеспечиваются реализация конституционных прав и свобод граждан Российской Федерации, достойное качество и уровень их жизни, суверенитет, независимость, государственная и

\footnotetext{
${ }^{1}$ Указ Президента Российской Федерации № 683 от 31 декабря 2015 г. «О Стратегии национальной безопасности Российской Федерации». URL: http://www.consultant.ru/cons/cgi/online.cgi?req=doc\&base=LAW\&n=191669 $\&$ fld $=134 \&$ dst $=1000000001,0 \&$ rnd $=0.8776376555106467 \# 08752438092157615$

${ }^{2}$ Федеральный закона № 172-Ф3 от 28 июня 2014 г. «О стратегическом планировании в Российской Федерации» (ред. от 18.07.2019). URL: http://www.consultant.ru/document/cons_doc_LAW_164841/c554568849952fc5f789 414f47081f6efb928177f/

${ }^{3}$ Указ Президента Российской Федерации № 683 от 31 декабря 2015 г. «О Стратегии национальной безопасности Российской Федерации». URL: http://www.consultant.ru/cons/cgi/online.cgi?req=doc\&base=LAW\&n=191669 $\&$ fld $=134 \&$ dst $=1000000001,0 \&$ rnd $=0.8776376555106467 \# 08752438092157615$

${ }^{4}$ Там же.
} 
Понятие «национальные интересы» в контексте национальной безопасности...

территориальная целостность, устойчивое социально-экономическое развитие Российской Федерации ${ }^{5}$.

Современной наукой накоплен основательный теоретический материал в изучении сущности феномена безопасность. Каждый из авторов, занимающихся этой проблемой, дает развернутую критику точек зрения оппонентов ${ }^{6}$. Однако критические замечания и подходы к определению сущности безопасности не имеют принципиальных различий. В большинстве случаев определения безопасности, имеющиеся в социально-гуманитарных науках, с учетом их содержания и смысла, будь то безопасность как отсутствие опасности для объекта, системы, равно их защищенность от опасностей, или способность объекта противостоять опасностям и угрозам, сохраняя свои системообразующие свойства и др., подразумевают гарантию бытия субъектов социального, экономического, политического, духовного, информационного общения ${ }^{7}$. Содержанием и смыслом существования субъекта является удовлетворение его потребностей, реализация его интересов.

Термин «национальные интересы» для российской науки сравнительно новый. Лишь последние четверть века идет процесс его теоретического осмысления. Есть ученые, которые отрицают положительный смысл (общетеоретическую состоятельность и практическую целесообразность) применения термина «национальные интересы» в политической реальности. Например, в силу его «кажущейся видимости» (ложности) $)^{8}$. Полагаем, что в наши дни явление «национальные интересы» обладает вполне определенными пространственно-временными характеристиками. Одним из объективных показателей (как отмечено выше) является целенаправленная государственная политика (совокупность социально-экономических, политико-организационных, правовых действий органов власти и управления), способствующая их реализации. Прав А.А. Кокошин, что «национальные интересы» - это категория реальных политических процессов, термин, уже имеющий сравнительно общепринятое значение ${ }^{9}$. Для других, в частности Б.Г. Капустина, использование этого феномена невозможно, потому что «единый "национальный интерес"» предполагает наличие внутри страны чего-то типа общей "культурной идентичности". В условиях же "мультикультурализма" или культурного плюрализма, характерного для многих наций мира, единое понимание общественного блага «будет иметь очень мало общего с идеей "национального интереса"»" ${ }^{10}$. Не будем углубляться в вопросы культурного плюрализма и мультикультурализма,- они являются предметом для отдельного рассмотрения. В контексте нашего исследования достаточно утверждения, что мультикультурализм в демократическом государстве - это концепция «социальной интеграции культур» (взаимного сотрудничества), основанная на принципах культурного плюрализма, толерантности и диалога ${ }^{11}$, противостоящая политике ассимиляции (слияния). О.Н. Астафьева пишет: «Этнокультурное многообразие не мешает формированию определенной гражданской идентификации, которая не тождественна социокультурной идентичности, тем более - национально-культурной (коллективной) идентичности, но является важной частью целостной идентификационной палитры, присущей людям, проживающим в рамках единого государственного образования» ${ }^{12}$.

\footnotetext{
${ }^{5}$ Там же.

${ }^{6}$ См.: Решетникова Г.А. Безопасность субъектов права: философский анализ понятия «безопасность» // Вестн. Удм. ун-та. Сер. Экономика и право. 2018. Т. 28, вып. 4. С. 591-597.

${ }^{7}$ Решетникова Г.А. Легальное понятие феномена «безопасность»: критический анализ // Вестн. Удм. ун-та. Сер. Экономика и право. 2019. Т. 29, вып. 6. С. 889.

${ }^{8}$ Фурман Д.Е. «Национальный интерес - псевдопонятие, аналогичное другому родственному псевдопонятию «классового интереса», очень удобное, в силу своей неопределенности и эмоциональной «зараженности», для политической полемики, но непригодное для научного обсуждения и анализа». Цит. по: Рековская И.Ф. Понятие «национальный интерес» в Российской общественно-политической жизни (сводный реферат) // Социальные и гуманитарные науки. Отечественная и зарубежная литература. Сер. 11: Социология. 1997. С. 91.

${ }^{9}$ Кокошин А.А. Национальные интересы, реальный суверенитет и национальная безопасность // Вопросы философии. 2019. URL: http://vphil.ru/index.php?option=com_content\&task=view\&id=1258

${ }^{10}$ Цит. по: Рековская И.Ф. Понятие «национальный интерес» в Российской общественно-политической жизни (сводный реферат). URL: https://cyberleninka.ru/article/n/97-04-018-025-ponyatie-natsionalnyy-interes-v-rossiyskoyobschestvenno-politicheskoy-zhizni-svodnyy-referat/viewer

${ }^{11}$ См.: Всеобщая Декларация ЮНЕСКО о культурном разнообразии. Принята 32-й сессией Генеральной конференции ЮНЕСКО. Париж, 2 ноября, 2001. URL: https://www.un.org/ru/documents/decl_conv/declarations/cultural_ diversity.shtml

${ }_{12}$ Астафьева О.Н. Культурная политика государства: вопросы о реально существующем и потенциально возможном // Знание, понимание, умение. 2008. № 4. С. 16.
} 
Неверно видеть в национальных интересах исключительно этническое основание. Разумеется, оно имеет значение, но не ограничивается им. Справедливы слова В.О. Ключевского: «Народ есть население, не только совместно живущее, но и совокупно действующее, имеющее общий язык и общие судьбы. ... Таковы...два тесно связанных между собой признака, обозначающие начало истории народа; самое раннее воспоминание его о самом себе и самая ранняя общественная форма, объединяющая его в каком-либо совокупном действии» ${ }^{13}$. Исторический опыт показывает, что для России географические (природно-климатические факторы, обширная территория) и геополитические условия (угроза внешних нападений) предопределили в качестве национального интереса упрочнение государства для обеспечения безопасности, мирного существования этнических, религиозных и иных социокультурных общностей. А. Галкин и Ю. Красин отмечают: «В современных развитых обществах этническое основание уже не играет сколько-нибудь значимой роли в определении национальных интересов. Эти общества становятся этнически смешанными, где национальная принадлежность деполитизируется и уже мало влияет на гражданское положение и, следовательно, на понимание национальных интересов» 14 . В соответствии со Стратегией государственной национальной политики Российской Федерации на период 2025 года (далее - Стратегия) приоритеты, принципы, основные направления, задачи и механизмы реализации государственной национальной политики России подчинены главным целям - обеспечению интересов государства, общества, человека и гражданина, укреплению государственного единства и целостности России, сохранению этнокультурной самобытности ее народов, сочетанию общегосударственных интересов и интересов народов России, обеспечению конституционных прав и свобод граждан ${ }^{15}$.

В научной литературе считается, что термины «национальные интересы» и «национальная безопасность» проистекают от современной интерпретации термина «нация» как социального и политического явления ${ }^{16}$. Представление о том, что согласие управляемых - это главный источник легитимности политических институтов является основной идеей теории общественного договора. В современной политической жизни она занимает одну из основных позиций, а идея, лежащая в ее основе, является ключевой для политического устройства современных демократических государств. Нельзя не согласиться с Т.Г. Понятовской в том, что «иное решение этого вопроса (иной концепт) предопределяет иную систему взглядов на государство...» ${ }^{17}$. Возникновению этой теории способствовал ряд обстоятельств. Наряду с научно-технической революцией, с развитием естественноправовой доктрины и позитивного права (юридических кодексов и науки о них), изменение, произошедшие в общей ориентации философии, обращенной к человеку и его земному существованию, явилось основополагающей предпосылкой ${ }^{18}$. По мнению О.Б. Соколова, в основе теории общественного договора лежит синтез двух элементов - индивидуализма ${ }^{19}$ и инструментального подхода к социальной кооперации и политическим институтам как частному ее проявлению ${ }^{20}$. В этом контексте

\footnotetext{
${ }^{13}$ Ключевский В.О. Сочинения: в 9 т. Т. 1: Курс русской истории. Ч. 1 / под ред. В.Л. Янина. М.: Мысль, 1987. C. 120 .

14 Галкин А., Красин Ю. Национальные интересы и национальная безопасность России. URL: http://www.observer.materik.ru/observer/N3-4_97/017.htm

${ }^{15}$ Пункты 1, 2 Указа Президента Российской Федерации № 1666 от 19 декабря 2012 г. «О стратегии государственной национальной политики Российской Федерации на период 2025 года. URL: http://base.garant.ru/ $70284810 /$

${ }^{16}$ Кокошин А.А. Указ. соч.

17 Понятовская Т.Г. Концептуальные основы системы понятий и институтов уголовного и уголовнопроцессуального права. Ижевск. 1996. С. 8.

${ }^{18}$ См.: Соколов Б.О. Концепции общественного договора в современной политической теории: дис. .... канд. полит. наук. СПб., 2014. С. 24.

${ }^{19}$ О.Б. Соколов под индивидуализмом понимает «...такой взгляд на общественное устройство, согласно которому индивид становится raison d'etre политической жизни; разнообразные варианты политического устройства соизмеряются с желаниями и целями конкретных индивидов. Более того, самый свой смысл и возможность существования политика получает в результате индивидуальных потребностей: в самосохранении, в безопасности - своей собственной и своих близких, - в гарантиях для индивидуальной предпринимательской деятельности и многих других» // Соколов О.Б. Указ.соч.

20 Эти ограничивающие человеческое поведение структуры создаются самими людьми, рационально преследующими свои интересы. Политические нормы представляются лишь как более удобный и надежный способ избежать непредвиденных опасностей, которыми чревато состояние анархии // Там же.
} 
Понятие «национальные интересы» в контексте национальной безопасности...

политика и политические институты, включая главный институт - государство, начинают толковаться преимущественно в инструментальном ключе как средство осуществления интересов индивида, реализации его потребностей, что в принципе было неприемлемым для античной философскополитической мысли, обусловленной всеобщей презумпцией, сформулированной Аристотелем: «Человек есть существо политическое» ${ }^{21}$. Л.В. Поляков отмечает: «Принудительная (встроенная в саму"человеческую природу") социальность человека избавляла любого античного политического мыслителя от необходимости логического обоснования самого факта "социальности". Человека дообщественного, т.е. до-политического согласно этой логике просто не может быть. А потому сам вопрос о том, как человеку совершить максимально эквивалентный обмен первичной "свободы" на гарантирующий ему безопасность социальный "порядок" принципиально не может быть задан. Его просто некому задавать» ${ }^{22}$. Т. Гоббс избрал для собственной политической концепции способного к рациональному выбору самодостаточного индивида, ставшего основной сутью политической жизни, ее основным субъектом. По выражению О.В. Горяинова, «идея человека, как центральное звено всей политико-правовой доктрины Гоббса, берет свое начало в фигуре "идеального" индивида, т.е. субъекта абсолютно свободного. Концепция "естественного состояния" функционирует в политикоправовой доктрине автора "Левиафана" в качестве способа выхода за пределы правовой и государственной реальности для их сущностного определения, ... является методологическим условием для адекватного объяснения государственно-правовых явлений...» ${ }^{23}$. Т. Гоббс, Д. Локк, Ж.Ж. Руссо, И. Кант и другие авторы, мыслящие в духе идей общественного договора, приходили к различным выводам о способах организации политической власти и по другим вопросам государственного строительства, но это - детали. Всех их объединяет одно: индивидуальные интересы являются основной причиной человеческого общения (взаимодействия). Отдельный человек является источником всего политического, главной целью политики и мерой ее эффективности (ст. 2 Конституции РФ является прямым этому подтверждением). Лишь то политическое устройство легитимно, которое содействует реализации индивидуальных потребностей. Причем эта легитимность приобретается в соответствии с согласием людей на ряд ограничений их личной свободы. Разумеется, в этом свою роль сыграли и реальные политические события, воодушевившие классиков общественного договора на создание своих концепций. В данном отношении политическая философия является отражением социальных изменений. Английская гражданская война $(1642-1651)$, когда страх перед насильственной смертью преобладал, позволила увидеть этот предел и сделать его отправным для философскополитического рассуждения Гоббса. «Гоббс в своей политической философии, - пишет Б. Капустин, - прав не столько теоретически, сколько практически, ибо преодоление состояния общественного коллапса и есть важнейшая ключевая задача. Во имя этой цели, - отмечает Б. Капустин, - и разрабатывается Гоббсом теория нового государства. Нового - не в смысле "очередного" и "сменяющего предыдущее", а в смысле беспрецедентности характера этого государств... Масштаб и новизну вставших задач Гоббс и передает подчеркиванием искусственного характера этого политического образования: Левиафан - искусственный "коллективный человек". Полис был естественным для древних греков, христианское государство - для средневековых европейцев. Для современников же Гоббса "экономических человеков" естественным является безгосударственное состояние "войны всех против всех". Но в нем невозможно жить. Чтобы жить, они должны совершить нечто для себя противоестественное - заняться политикой как целенаправленным и коллективным устроением сво-

\footnotetext{
${ }^{21}$ Поляков Л.В. О понимании свободы. Перечитывая И. Берлина // Полития. 2009. № 1. URL: http://www.intelros.ru/ intelros/reiting/reyting_09/material_sofiy/8471-o-ponimanii-svobody-perechityvaya-iberlina.html

${ }^{22}$ Там же.

${ }^{23}$ Горяинов О.В. Политико-правовые идеи Т. Гоббса и их влияние на философию французского просвещения: Теоретико-методологический историко-правовой аспекты: автореф. дис. на соискание ученой степени канд. юрид. наук. М., 2008; По мнению Б. Капустина, «"естественное состояние" - не описание, пусть абстрактнотеоретическое, какой-то эпохи или формы человеческой жизни. Это, прежде всего, аналитическая модель, позволяющая увидеть важную тенденцию новоевропейской жизни - тенденцию эрозии старых, "естественных" этико-религиозных форм регуляции человеческих отношений под влиянием нового буржуазного "рационального" индивидуализма, а вместе с ними - и покоящихся на них форм политической и правовой организации. Домысленная "до конца", до своего логического предела, которыми и оказывается "война всех против всех", эта тенденция представала тотальным разрушением самих основ социальной жизни» // Капустин Б. Очерки истории западноевропейского либерализма (XVII-XIX вв.). М., 2004. С. 9, 10.
} 
его общежития. Они, будучи естественным образом частными лицами, должны как-то перевернуться и выступить в искусственном для них виде граждан, то есть публично-политических субъектов» ${ }^{24}$. Современная интерпретация термина «нация» приобретает иной дополнительный (политический) смысл: «совокупность граждан, чей коллективный суверенитет и воля образуют государство» ${ }^{25}$. Если обратиться к Конституции России, ответ на вопрос о происхождении государства, о его основной идее очевиден. «Мы, многонациональный народ Российской Федерации, - говорится в преамбуле, ...принимаем Конституцию Российской Федерации». Объединяясь в целостное (неделимое) демократическое государство, многонациональный народ России провозглашает себя носителем суверенитета и единственным источником власти. Принятие народом действующей Конституции легитимировало современное Российское государство, придав ему соответствующую политико-юридическую форму. В настоящей работе соотношение понятий «народ» и «нация», их специальное использование остаются за рамками анализа. Поэтому употребляются нами в качестве синонимичных понятий, в соответствии со Стратегией, где под российской нацией понимается многонациональный народ Российской Федерации и все составляющие его народы (этнические общности) ${ }^{26}$.

По мнению А.А. Кокошина, как бы не интерпретировался термин «нация» научным сообществом, его использование в большей степени как синонима государства - это политическая реальность современности, которую нельзя игнорировать. В этом значении термин «нация» используется в международном праве, в международно-правовых документах $\mathrm{OOH}^{27}$. Такое суждение дает повод для постановки вопроса о тождественности понятий «национальные интересы» и «государственные интересы», «нация» и «государство», соответственно. Р.Р. Улитин пишет: «...Зачастую государственные интересы противопоставляют национальным и общественным. Но если мы говорим о национальном государстве или о нации - государстве, имея в виду неэтнический (в западном понимании) компонент данного понятия, то мы вправе говорить о национальных интересах и интересах государственных, если не как о синонимах, то, во всяком случае, как о близко связанных и взаимодополняемых понятиях... Поэтому мы вправе использовать также и понятие "национально-государственные интересы" ${ }^{28}$. А.А. Борисенков считает, что с формально-логической точки зрения национальные интересы и интересы государства - это разные виды интересов, которые как-то между собой связаны, но как виды они неодинаковые и их нельзя смешивать ${ }^{29}$. Действительно, государство является основным политическим институтом олицетворения национальных интересов представляемой им социально-политической общности (нации) и ее защиты. Это одна из важнейших функций государства. Собственно, на этом покоится легитимность государственной власти. В международных отношениях от имени нации выступает государство, а выражаемые государством интересы воспринимаются как национальные. Поэтому вряд ли оправдано недоумение А.А. Борисенкова по поводу формулировки «национальные интересы Российской Федерации», используемой в Стратегиях 2000 и 2015 гг., словно речь идет о смешении двух разных видов интересов ${ }^{30}$. Тем более, ему самому понятно, что «...термином "Российская Федерация" обозначается не общество или нация, а государство», призванное управлять обществом и совсем не тождественное самой нации и поэтому имеющее свои особые, государственные интересы ${ }^{31}$.

Но привлечение народа к политике осуществляется и гражданским обществом. Институты гражданского общества играют важную роль в формировании, обеспечении и защите национальных ин-

\footnotetext{
${ }^{24}$ Капустин Б. Очерки истории западноевропейского либерализма (XVII-XIX вв.). М., 2004. С. 10.

${ }^{25}$ Хобсбаум Э. Цит. по: Босяцкий А., Любашиц В.Я., Филиппова М.К. Возникновение национального государства как государства современного типа // Территория новых возможностей. Вестник ВГУЭС. 2015. № 4 (31). С. 124.

${ }^{26}$ Пункт 8 Указа Президента Российской Федерации № 1666 от 19 декабря 2012 г. «О стратегии государственной национальной политики Российской Федерации на период 2025 года. URL: http://base.garant.ru/70284810/

${ }^{27}$ Кокошин А.А. Указ. соч.

${ }^{28}$ Улитин Р.Р. Соотношение понятий «национальный интерес» и «национальная безопасность» в трудах западных и отечественных исследователей // Вестник Нижегород. ун-та им. Н.И. Лобачевского. Сер.: Международные отношения, Политология, Регионоведение. 2003. № 1. С. 131.

${ }^{29}$ Борисенков А.А. Представления об индивидуальном интересе и их значение для изучения национальных интересов // Вестник Сибир. ин-та бизнеса и информационных технологий. 2015. № 3 (15). С. 62.

30 Там же.

${ }^{31}$ Там же.
} 
Понятие «национальные интересы» в контексте национальной безопасности...

тересов. Об этом прямо указано в п. 6 Стратегии 2015 г. ${ }^{32}$ Подменять государственные интересы национальными или считать государственные интересы простыми производными от национальных интересов, либо отождествлять их неверно. Впрочем, так же как неверно и интерпретировать термин «нация», руководствуясь лишь одним из его значений (в самом обобщенном виде этническим, социальным, политическим и т.д.). Так, как отмечалось выше, этнический компонент - не единственный, однако для России имеющий самостоятельное и принципиальное значение, отчетливо отражающийся в деятельности государства. По-прежнему основными вопросами государственной национальной политики России (согласно Стратегии), требующими особого внимания, являются следующие: сохранение и развитие культур и языков народов Российской Федерации, укрепление их духовной общности; обеспечение прав коренных малочисленных народов и национальных меньшинств; создание дополнительных социально-экономических и политических усилий для обеспечения прочного национального и межнационального мира и согласия на Северном Кавказе; поддержка соотечественников, проживающих за рубежом, содействие развитию их связей с Россией ${ }^{33}$. Полагаем, что в контексте национальной безопасности феномен «нация» вбирает в себя всё многообразие смыслов (вышеперечисленных значений), становясь единым комплексным и системным понятием, приобретшим качественно иной смысл. Адекватное отражение национальных интересов зависит от соразмерного учета всех компонентов общественной жизни, включая политический, внешнеполитический, экономический, социальный, этнический, культурный и другие компоненты, а также непростые в оценке, однако имеющие большое значение духовные ценности, традиции и обычаи многонационального народа.

В Концепции национальной безопасности Российской Федерации 1997 г. национальные интересы устанавливались как система. Отмечалось, что система национальных интересов России определяется совокупностью основных интересов личности, общества и государства ${ }^{34}$. Идя в этом направлении (рассматривая «национальные интересы» как систему), из определения «системы» следует, что главными ее свойствами являются целостность и единство, устанавливающиеся в результате взаимосвязи и взаимодействия каждого из элементов системы. Система приобретает новые, качественно иные свойства, которыми элементы системы не обладают (свойство эмерджетности). Какие качественно иные свойства возникают при такой (вышеуказанной) формулировке национальных интересов, кроме их заявления (декларации)? Полагаем, ближе к этому свойству (эмерджентности) формулировка национальных интересов, содержащаяся в Стратегии 2015 г., где интересы личности, общества и государства «опредмеченные» объективно значимыми потребностями заключаются в их удовлетворении. Целостность системы означает, что каждый элемент системы вносит свой вклад в реализацию собственно-целевой функции системы. Из этого следует, что в контексте национальной безопасности Российской Федерации национальные интересы «опредмеченные» потребностями личности, общества и государства, не сводятся к простой их совокупности (сумме). Это целостное, единое и неделимое явление, выражающее объективно значимые потребности личности, общества и государства, удовлетворение которых гарантирует существование и развитие всей нации.

Поступила в редакцию 12.04.2020

Решетникова Гульнара Аликовна, кандидат юридических наук, доцент

ФГБОУ ВО «Удмуртский государственный университет»

426034, Россия, г. Ижевск, ул. Университетская, 1 (корп. 4)

\footnotetext{
32 Пункт 6 Указа Президента Российской Федерации № 683 от 31 декабря 2015 г. «О Стратегии национальной безопасности Российской Федерации». URL: http://www.consultant.ru/cons/cgi/online.cgi?req=doc\&base=LAW $\& \mathrm{n}=191669 \&$ fld $=134 \& \mathrm{dst}=1000000001,0 \& \mathrm{rnd}=0.8776376555106467 \# 08752438092157615$

${ }^{33}$ Пункт 5 Указа Президента Российской Федерации № 1666 от 19 декабря 2012 г. «О стратегии государственной национальной политики Российской Федерации на период 2025 года. URL: http://base.garant.ru/70284810/

${ }^{34}$ Концепция национальной безопасности Российской Федерации. Утверждена Указом Президента РФ от 17 декабря 1997 г. (в ред. Указа Президента РФ № 24 от 10.01. 2000. URL: http://www.consultant.ru/cons/cgi/ online.cgi ?req $=$ doc\&base $=$ LAW $\& n=25683 \&$ fld $=134 \& d s t=1000000001,0 \&$ rnd $=0.8752791882194755 \# 04880663324163268$
} 


\section{G.A. Reshetnikova}

\section{THE CONCEPT OF "NATIONAL INTERESTS" IN THE CONTEXT OF NATIONAL SECURITY} OF THE RUSSIAN FEDERATION

DOI: $10.35634 / 2412-9593-2020-30-3-438-444$

"National interests" form the basis for the formation of not only foreign, but also the internal policy of the state. An objective indicator of this is the totality of socio-economic, political, organizational, legal actions of government bodies and management on their implementation. The practical expediency of the phenomenon of "national interests" depends on its theoretical consistency. As a new phenomenon for modern Russia, "national interests" require its understanding and scientific development. Guided by the provisions of political documents in the field of ensuring national security of the Russian Federation, relying on the results obtained by researchers in the field of philosophy, political science, the history of legal and political studies, ethnography, etc., the author of the article has undertaken a search for the conceptual nature and essential properties of this multicomponent phenomenon.

Keywords: security, national interests, national security, nation, objectively significant interests of an individual, society and state.

Reshetnikova G.A., Candidate of Law, Associate Professor Udmurt State University

Universitetskaya st., 1/4, Izhevsk, Russia, 426034 